\section{References}

1. Brantigan OC, Mueller E, Kress MB. A surgical approach to pulmonary emphysema. Am Rev Respir Dis. 1959;80:194-206.

2. Cooper JD, Trulock EP, Triantafillou AN, Patterson GA, Pohl MS, Deloney PA, et al. Bilateral pneumectomy (volume reduction) for chronic obstructive pulmonary disease. J Thorac Cardiovasc Surg. 1995;109: 106-16.
3. Bloch KE, Weder W, Boehler A, Zalunardo MP, Russi EW. Successful lung volume reduction in a child with severe air flow obstruction and hyperinflation due to constrictive bronchiolitis. Chest. 2002;122:745-50.

4. Cohen G, Saglani S, Dinwiddie R, Webb M, Jaffe A. An alternative to lung transplantation. Pediatr Pulmonol. 2003;36:357-8

5. Mancuso M, Pacchioni D, Ruffini E, Cavallo A, Filosso P, Viale A, et al. Successful bilateral lung volume reduction in a child with emphysema from bronchiolitis obliterans. J Thorac Cardiovasc Surg. 2004;128:645-7.

\title{
Pathologic correlates of heparin-free donation after cardiac death in lung transplantation
}

\author{
Chase R. Brown, BS, ${ }^{a}$ Alexis E. Shafii, MD, ${ }^{\mathrm{b}}$ Carol F. Farver, MD,${ }^{\mathrm{c}}$ Sudish C. Murthy, MD, PhD, \\ Gösta B. Pettersson, MD, PhD, ${ }^{\mathrm{b}}$ and David P. Mason, MD, ${ }^{\mathrm{b}}$ Cleveland, Ohio
}

Recent experience with donation after cardiac death (DCD) for lung transplantation has been excellent. ${ }^{1}$ Despite this fact, use of DCD donors has been limited because of concerns that graft quality may be compromised. As an additional barrier to widespread acceptance, DCD procurement is shrouded with technical concerns, specifically regarding the timing of heparin administration. Prearrest systemic heparinization during DCD procurements is not a consistent policy among centers because of the fear that heparin might accelerate death. Despite any evidence, most transplant centers decline DCD lungs for fear of thromboembolism if procured heparin free. ${ }^{2}$ To address this specific concern, DCD lungs declined for transplantation because of lack of systemic heparin were harvested and examined for gross and microscopic thrombosis.

\section{CLINICAL SUMMARY}

A 40-year-old man sustained irreversible neurologic injury from a drug overdose. He did not meet brain death criteria, but the family consented him for Maastricht Category III organ donation. Because the hospital DCD protocol did not permit systemic heparinization before withdrawal of care, all national transplant centers declined the lungs, which were procured for research.

\footnotetext{
From the Cleveland Clinic Lerner College of Medicine, ${ }^{\text {a }}$ Department of Thoracic and Cardiovascular Surgery, ${ }^{\mathrm{b}}$ Department of Anatomic Pathology, ${ }^{\mathrm{c}}$ Cleveland Clinic, Cleveland, Ohio.

Disclosures: Authors have nothing to disclose with regard to commercial support. Received for publication Dec 10, 2012; accepted for publication Jan 17, 2013; available ahead of print Feb 18, 2013.

Address for reprints: David P. Mason, MD, Department of Thoracic and Cardiovascular Surgery, Cleveland Clinic, 9500 Euclid Ave, J4-1, Cleveland, OH 44195 (E-mail: masond2@ccf.org)

J Thorac Cardiovasc Surg 2013;145:e49-50

$0022-5223 / \$ 36.00$

Copyright $(2013$ by The American Association for Thoracic Surgery

http://dx.doi.org/10.1016/j.jtcvs.2013.01.036
}

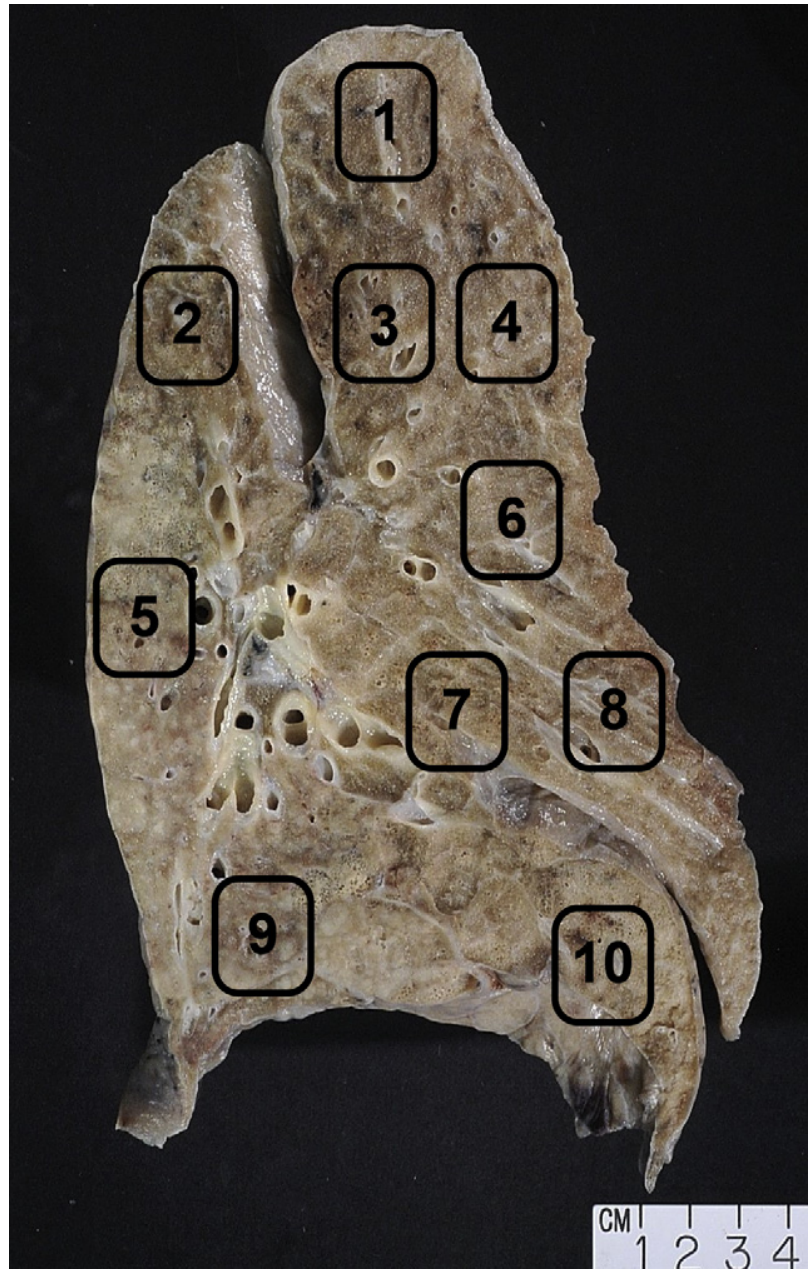

FIGURE 1. Map of lung sectioning for microscopic analysis.

During the DCD procurement, cardiac arrest occurred 70 minutes after withdrawal of care and extubation. After 5 minutes of electrocardiographic silence, the donor was 

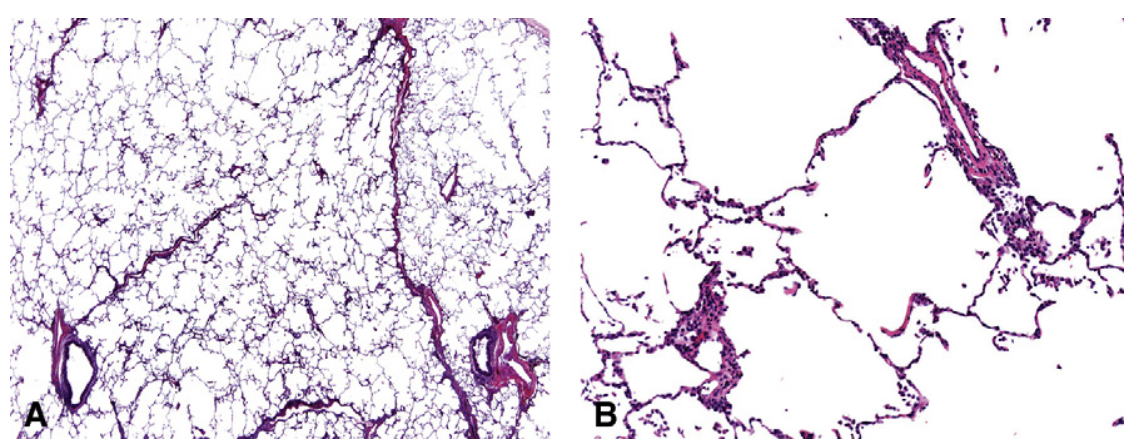

FIGURE 2. Hematoxylin-eosin staining of a representative lung section with no microvascular thrombi at $2.5 \times$ magnification (A) and $100 \times$ magnification $(B)$.

reintubated and the lungs reinflated. Concomitantly, a midline sternotomy was performed and the pleural cavities were packed with ice. After cannulation of the pulmonary artery, the heart was exsanguinated and the left atrial appendage excised. Three liters of ice-chilled Perfadex (Vitrolife, Kungsbacka, Sweden) preservation solution enriched with 50,000 IU heparin were flushed antegrade through the pulmonary artery. After standard en bloc lung extirpation, an additional $1 \mathrm{~L}$ was flushed retrograde through the pulmonary vein ostia. Effluent was collected and examined for gross clot. The lungs were transported on ice and fixed subsequently in $10 \%$ formalin at physiologic pressure $(18 \mathrm{~mm} \mathrm{Hg})$. Each lung was cut in 5-mm sagittal sections and analyzed systematically from apex to base for gross occlusive clot. In addition, a total of 20 tissue sections (10 sections per lung) were collected from the right and left lung (Figure 1) for microscopic examination. Each tissue section was paraffin embedded and stained with hematoxylin-eosin. A pulmonary pathologist evaluated each tissue section for microvascular thrombi with 100 high-power fields (HPFs), resulting in a total evaluation of 2000 HPFs for the complete lung.

Evaluation of the antegrade and retrograde effluent revealed no significant clot formation. Gross macroscopic assessment of each sagittal plane found no occlusive central or peripheral clot. Microscopic analysis revealed no microvascular thrombi in the alveolar capillaries or pulmonary vasculature in any HPF (0/2000). Focal areas of acute pneumonia were identified. Representative histology at $12.5 \times$ and $100 \times$ magnification is presented in Figure 2.

\section{DISCUSSION}

The first human lung transplantation was performed using a DCD donor who was heparinized after cardiac death. Although the standard protocol in the United States is to administer heparin before withdrawal of care, ${ }^{2}$ some centers restrict heparin until after cardiac standstill because of ethical concerns about hastening death. Although pathologic correlates of heparin-free DCD procurement have not been described previously, the vast majority of these potential donor lungs are declined for fear of postmortem thrombosis.

In this study, we demonstrated complete absence of gross and microvascular thrombi in human lungs that did not receive heparin before declaration of death. Despite the extended agonal phase of 70 minutes in this donor, no clot formation was identified when the lungs were retrieved and flushed with heparinized pulmoplegia. This supports our recent experimental findings of delayed heparin administration in a pig DCD model, in which it appears that heparin can be administered at least 25 minutes after cardiac standstill without the formation of gross or microvascular thrombi in the lungs. ${ }^{3}$

Potential explanations of this lack of thrombosis after DCD arrest are as follows: (1) passive circulation after cardiac arrest continues for several minutes as a result of an intrinsic gradient between the systemic arterial and central venous pressures ${ }^{4}$ (2) the period between cardiac arrest and organ procurement is brief, and (3) antegrade and retrograde flushing with heparinized pulmoplegia effectively eliminates any residual blood. ${ }^{5}$

We conclude that nonheparinized Maastricht Category III DCD human lungs do not appear to harbor thrombi when harvested using antegrade and retrograde flush enriched with heparin. Although further investigation is warranted, evidence suggests that these organs can be used without concern for thromboembolism.

\section{References}

1. Mason DP, Brown CR, Murthy SC, Vikil N, Lyon C, Budev MM, et al. Growing single-center experience with lung transplantation using donation after cardiac death. Ann Thorac Surg. 2012;94:406-12.

2. Bernat JL, D'Alessandro AM, Port FK, Bleck TP, Heard SO, Medina J, et al. Report of a national conference on donation after cardiac death. Am J Transplant. 2006;6:281-91.

3. Keshava H, Farver C, Brown CR, Shafil AE, Murthy SC, Yun JJ, et al. Timing of heparin and thrombi formation in donor lungs after cardiac death. Thorac Cardiovasc Surgeon. December 5, 2012 [Epub ahead of print].

4. Frenneaux M. Cardiopulmonary resuscitation: some physiological considerations. Resuscitation. 2003;58:259-65.

5. Van De Wauwer C, Neyrinck AP, Geudens N, Rega FR, Verleden GM, Verbeken E, et al. Retrograde flush following topical cooling is superior to preserve the non-heart-beating donor lung. Eur J Cardiothorac Surg. 2007;31:1125-32. 